\title{
Avaliação da situação vacinal e a percepção de acadêmicos dos cursos da área da saúde de um centro universitário particular de uma cidade do estado do Pará
}

\author{
Evaluation of the vaccination situation and the perception of academics of health courses \\ in a private university center in a city in the state of Pará
}

Evaluación de la situación de vacunación y percepción de los académicos de los cursos de salud en un centro universitario privado en una ciudad en el estado de Pará

Elem Cristina Rodrigues Chaves ${ }^{1 *}$, Kleber das Neves Trindade Júnior ${ }^{1}$, Ismari Perini Furlaneto ${ }^{2}$, Tinara Leila de Souza Aarão ${ }^{1,2}$, Maria Helena Rodrigues de Mendonça ${ }^{1,2}$.

\section{RESUMO}

Objetivo: Avaliar o perfil e a percepção dos discentes dos cursos da área de saúde em uma instituição privada de ensino superior de uma cidade do estado Pará acerca do calendário vacinal. Métodos: Trata-se de estudo descritivo, analítico e quantitativo da situação vacinal, realizado em uma instituição privada de ensino superior localizada em uma cidade do Pará. Resultados: Após análise dos dados, foi observado associação significativa no status vacinal desatualizado dos discentes da saúde e a faixa etária de 18 a 22 anos $(p=0,0381)$, a menor exigência do cartão vacinal no estágio extracurricular $(p=0,0035)$ e a menor percepção sobre PNI e consequências da não imunização ( $p=0,0001$ e 0,0141$)$. Ademais, a menor adesão as vacinas pelo curso de Biomedicina ( $p=0,0389)$ e maior em Enfermagem $(p=0,0389)$, menor frequência de cartão atualizado em Nutrição e Biomedicina $(p<0,0001)$ e maiores orientações acerca da vacinação nos dois anos iniciais ao curso $(<0,0001)$. Conclusão: Observa-se negligencias quanto ao perfil vacinal a partir da baixa frequência de vacinação e o elevado risco aos graduandos da saúde, dispõem às instituições a necessidade de medidas de intensificação à nível da biossegurança e verificação precoce e constante do cartão vacinal.

Palavras-chave: Saúde do trabalhador, Risco ocupacional, Imunização, Recusa de vacinação.

\begin{abstract}
Objective: To evaluate the profile and perception of students of health courses in a private higher education institution in a city in pará state about the vaccination calendar. Methods: This is descriptive, analytical and quantitative study of the vaccination situation, carried out in a private institution of higher education located in a city in Pará. Results: After data analysis, a significant association was observed in the outdated vaccination status of health students and the age group from 18 to 22 years $(p=0.0381)$, the lower requirement of the vaccination card in the extracurricular stage $(\mathrm{p}=0.0035)$ and the lower perception about $\mathrm{PNI}$ and consequences of non-immunization $(p=0.0001$ and 0.0141$)$. Moreover, the lower adherence of vaccines by the course of Biomedicine $(p=0.0389)$ and higher in Nursing $(p=0.0389)$, lower frequency of updated card in Nutrition and Biomedicine $(p<0.0001)$ and higher guidelines for vaccination in the two years prior to the course $(<0.0001)$. Conclusion: There is negligence regarding the vaccination profile from the low frequency of vaccination and the high risk to health undergraduates, the institutions have the need for measures of intensification in terms of biosafety and early and constant verification of the vaccination card.
\end{abstract}

Keywords: Worker health, Occupational risk, Immunization, Vaccination refusal.

${ }^{1}$ Centro Universitário FIBRA, Belém - PA. *E-mail: elemcrc@gmail.com

2 Centro Universitário Metropolitano da Amazônia (UNIFAMAZ), Belém - PA. 


\section{RESUMEN}

Objetivo: Evaluar el perfil y la percepción de los estudiantes de los cursos de salud en una institución privada de educación superior en una ciudad en pará estado sobre el calendario de vacunación. Métodos: Se trata de estudio descriptivo, analítico y cuantitativo de la situación de vacunación, realizado en una institución privada de educación superior ubicada en una ciudad de Pará. Resultados: Después del análisis de datos, se observó una asociación significativa en el estado de vacunación anticuado de los estudiantes de salud y del grupo de edad de 18 a 22 años (p-0.0381), el requisito más bajo de la tarjeta de vacunación en la etapa extracurricular ( $p-0.0035)$ y la menor percepción sobre la PNI y las consecuencias de la no inmunización ( $p$ 0.0001 y 0.0141$)$. Por otra parte, la menor adherencia de las vacunas por el curso de Biomedicina ( $p-0.0389)$ y superior en Enfermería ( $p$-0.0389), menor frecuencia de tarjeta actualizada en Nutrición y Biomedicina $(p<0.0001)$ y mayores pautas para la vacunación en los dos años anteriores al curso $(<0.0001)$. Conclusión: Hay negligencia en cuanto al perfil de vacunación por la baja frecuencia de vacunación y el alto riesgo para los estudiantes de salud, las instituciones tienen la necesidad de medidas de intensificación en términos de bioseguridad y verificación temprana y constante de la tarjeta de vacunación.

Palabras clave: Salud de los trabajadores, Riesgo laboral, Inmunización, Rechazo de vacunación.

\section{INTRODUÇÃO}

Incorporada por Edward Jenner, em 1798, a "vaccine" atua sensibilizando e estimulando o sistema imunológico a produzir anticorpos visando a prevenção do desenvolvimento clinico a determinada infecção que, em certos casos, é a única medida para interromper a cadeia de transmissão, auxiliar seu controle e erradicação (BRAZ RM, et al., 2016; SORGATTO SV, et al., 2018). Além dos benefícios individuais da vacinação, ressalta sua importância no meio coletivo caracterizado pelo aumento do nível de imunidade da população (rebanho), frente a elevada proporção de pessoas vacinadas, servindo como barreira de proteção à disseminação de doenças (APS LRMM, et al., 2018; DURÃES FAA, et al., 2019).

O Brasil é reconhecido pelo seu amplo Programa Nacional de Imunização (PNI), cujo objetivo visa coordenar as ações de imunizações e erradicar ou controlar doenças mediante a vacinação da população, de forma rotineira, tentando alcançar coberturas vacinais de 95\%. O PNI mantém uma política de incentivos à modernização tecnológica e destaca-se quanto ao Calendário Nacional de Vacinação que, atualmente, conta com 18 imunobiológicos para todas as faixas etárias (BRASIL, 2019).

Além das vacinas presentes no calendário, os Centros de Referência de Imunobiológicos (CRIE), disponibilizam outras vacinas para portadores de condições clínicas especiais. Ademais, a Sociedade Brasileira de Imunização (SBIm) estabelece o Calendário Vacinal Ocupacional aos profissionais da saúde, nesse sentido, recomendam as vacinas: hepatite $B$, meningocócicas conjugadas $A C W Y / C$, febre amarela, tríplice viral, hepatite $A$, tetra viral, varicela, dupla adulto, influenza, tríplice bacteriana e meningocócica $B$ com objetivo de fornecer a proteção e o trabalho seguro (SBIm, 2019;2020).

Acadêmicos e profissionais da saúde encontram-se constantemente expostos aos riscos ocupacionais, sobretudo, de natureza biológica oriundos das práticas inerentes. Tais práticas podem expor tanto discentes quanto os profissionais habilitados os quais entram em contato com indivíduos portadores de doenças infectocontagiosas ou amostras biológicas contaminadas. Essa população, quando não imunizada, possui maiores riscos de infecção e, consequentemente, a disseminação em meio intra e/ou extra ocupacional (MORAIS LRGL, et al., 2017; NEGRINHO NBS, et al., 2017).

Segundo a Organização Pan-americana de Saúde (OPAS), a América Latina possui um percentual entre 1 e $4 \%$ de notificações de doenças ocupacionais, todavia, os dados oficiais no Brasil contabilizam somente trabalhadores regidos pela consolidação das leis do trabalho (CLT), categorizando assim a subnotificação de acidentes ocupacionais (OPAS, 2012; SANTOS JR, 2018). Gomes SCR e Caldas AJM (2019) relatam que, mundialmente, por ano, ocorram 926 mil acidentes perfurocortante entre profissionais e, entre 2000 e 2030 , estima-se em média 145 óbitos pelo vírus da hepatite $\mathrm{C}$ e 736 pelo vírus da imunodeficiência humana (HIV). 
Nesse contexto, as instituições de saúde e educação têm um papel significativo na manutenção da situação vacinal atualizada de profissionais e acadêmicos, além de estabelecer propostas com fins profiláticos visando controle/eliminação dos riscos ocupacionais. De acordo com Art. $1^{\circ}$ do projeto de Lei $n^{\circ} 1.429 / 2019$, permanece obrigatória apresentação do cartão de vacinação apenas a crianças e adolescentes para realização de matrícula em instituições nas redes públicas e privadas de educação, excluindo matriculas a serem realizadas em instituições de nível superior, contrapondo, o projeto de Lei $n^{\circ} 3530$ inclui comprovação de vacinação em universidades públicas, no entanto, apenas aos discentes menor de dezoito anos (BRASIL, 2004; 2019).

Independente dos projetos, é notório a isenção da comprovação do cartão vacinal aos discentes de nível superior, corroborando uma maior exposição à essas doenças. A permanência de determinado agente patogênico em uma população depende da presença de pessoas suscetíveis, portanto, o estado de imunização dos discentes e profissionais de saúde é de extrema importância devido ao contato constante com doentes e materiais biológicos. Com isso a importância de estudos que visem conhecer a imunidade individual dos discentes e o conhecimento dos mesmos para desenvolver estratégias que visem ampliar o conhecimento e minimizar os riscos de doenças imunopreviníveis.

O presente estudo tem por objetivo avaliar o perfil e a percepção dos discentes dos cursos da área de saúde em uma instituição privada de ensino superior de uma cidade do estado Pará acerca do calendário vacinal.

\section{MÉTODOS}

Trata-se de um estudo observacional do tipo transversal, de caráter descritivo e analítico e abordagem quantitativa da situação vacinal, realizado em uma instituição privada de ensino superior (IES) localizada em uma cidade do Pará A população alvo foi constituída por indivíduos de ambos os sexos com idade igual ou superior a 18 anos, regularmente matriculados nos seguintes cursos da referida IES e que formaram turmas do primeiro ao penúltimo semestre: Biomedicina e Nutrição (oito semestres), Enfermagem e Farmácia (dez semestres).

Foram excluídos os acadêmicos do último semestre de cada curso por estarem cursando o Estágio Curricular Supervisionado Obrigatório e, desta forma disporem de tempo exíguo para o preenchimento do questionário, além de discentes do curso de Odontologia devido não formação de todos os semestres. Para definição da amostra, foi considerada uma população igual a 787 alunos e margem de erro de $5 \%$, resultando em um tamanho amostral mínimo igual a 266 discentes selecionados por amostragem de conveniência.

A obtenção dos dados foi realizada por meio de um questionário auto aplicado adaptado de Chehuen $\mathrm{N}$, et al. (2010), composto por 21 perguntas referente ao curso, status vacinal, conhecimento relacionado ao calendário vacinal e importância da vacina, além de informações sobre obstáculos para imunização. $O$ recrutamento dos discentes foi realizado nas dependências da IES e contou com uma abordagem baseada na breve apresentação do projeto, seguido do encaminhamento dos discentes interessados em participar da pesquisa a uma sala reservada, da apresentação do projeto e da aplicação do TCLE e do questionário.

Os dados foram tratados segundo a sua natureza, sendo expressos sob a forma de frequências absoluta e relativa e as associações foram testadas com o auxílio do teste Exato de Fisher ou teste $G$ de independência, seguido da Análise de Resíduos do Qui-Quadrado para em caso de significância estatística. Todos os testes foram executados com o auxílio do programa BioEstat 5.0 e foi adotado o nível de significância igual a $5 \%$. O estudo atendeu os princípios éticos da Resolução do Conselho Nacional de Saúde (CNS) $n^{\circ}$ 466/12 e recebeu aprovação do Comitê de Ética e Pesquisa (CAAE: 11065119.9.0000.8187; Parecer no: 3.296.203).

\section{RESULTADOS E DISCUSSÃO}

Participaram do estudo 363 discentes, com média de idade igual a 21,6 anos (IC95\% 21,1-22,1), variando entre 18 e 52 anos; maioria era do sexo feminino (280/363, 77,1\%, IC95\% 72,5 - 81,2; p<0,0001). Considerando a situação do cartão vacinal, 50,0\% (179/358) declararam tê-lo atualizado, não sendo 
observada associação entre sexo e situação do cartão vacinal $(p=0,8023)$. No entanto, notou-se associação entre os mais jovens e a ausência de atualização do cartão e da faixa etária entre 23 e 27 anos e a manutenção do cartão atualizado $(p=0,0381)$ (Tabela 1).

Tabela 1 - Perfil dos participantes do estudo de acordo com sexo e faixa etária, segundo a situação do cartão vacinal.

\begin{tabular}{|c|c|c|c|}
\hline \multirow[b]{2}{*}{ Variável } & \multicolumn{2}{|c|}{ Situação do cartão vacinal } & \multirow[b]{2}{*}{ p-valor* } \\
\hline & $\begin{array}{c}\text { Atualizado } \\
n ; \%\end{array}$ & $\begin{array}{c}\text { Não atualizado } \\
n ; \%\end{array}$ & \\
\hline \multicolumn{4}{|l|}{ Sexo } \\
\hline $\begin{array}{l}\text { Masculino } \\
\text { Feminino }\end{array}$ & $\begin{array}{c}40 ; 22,3 \\
139 ; 77,7 \\
\end{array}$ & $\begin{array}{c}43 ; 24,0 \\
136 ; 76,0\end{array}$ & 0,8023 \\
\hline \multicolumn{4}{|l|}{ Faixa etária (anos) } \\
\hline 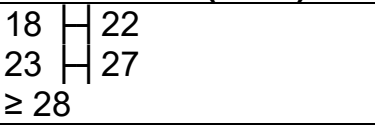 & $\begin{array}{c}129 ; 72,1^{\mathrm{a}} \\
32 ; 17,9^{\mathrm{b}} \\
18 ; 10,0 \\
\end{array}$ & $\begin{array}{c}149 ; 83,3^{\mathrm{b}} \\
18 ; 10,0^{\mathrm{a}} \\
12 ; 6,7\end{array}$ & $0,0381^{\dagger}$ \\
\hline
\end{tabular}

Legenda: ${ }^{*}$ Teste Exato de Fisher ou Teste G de independência/Análise de Resíduos do Qui-Quadrado.

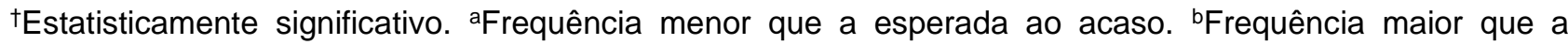
esperada ao acaso. Fonte: Chaves ECR, et al., 2020.

Segundo Araújo TM, et al. (2019) e, Cardin VSG e Nery LMG (2019), a hesitação vacinal é categorizada por inúmeros fatores como grau de confiança, baixa percepção de risco, acessibilidade, questões religiosas e políticas, sendo uma tendência progressiva e preocupante, sobretudo, no âmbito desenvolvimento profissional.

Diversos estudos relatam o perfil da situação vacinal descrito e relaciona-o à baixa percepção de risco e a falsa visão da saúde integra presente no público jovem, o qual interfere a lógica de profilaxia, molda sua adesão a programas de prevenção e, considerando o alto risco de exposição a material biológico, esses alunos destacam-se como grupo de risco para diversas infecções imunopreveníveis (SILVA RGM e NASCIMENTO VF, 2017; ARAUJO TM, et al., 2019).

Um dos imunobiológicos presentes no Calendário Vacinal Ocupacional é a tríplice viral, altamente imunogênica para sarampo, rubéola e caxumba, considerada a única medida de prevenção. Todavia, no presente estudo foi possível observar uma baixa cobertura vacinal no Brasil desde 2016, como resultado, relata a reemergência do sarampo no período de fevereiro de 2018 a junho de 2019, com maior percentual de casos na faixa de 15 a 29 anos, corroborando a maior susceptibilidade desse público diante o status vacinal e, quando tratando de estudantes e profissionais da saúde, a exposição e os risco de transmissão no meio intra e extra ocupacional são preocupantes (BRASIL, 2019; CHAVES ECR, et al., 2020).

De acordo com Ministério da Saúde (2020), 21 estados permanecem com circulação ativa do vírus do sarampo e, como consequência da infecção, Mina MJ, et al. (2019) destaca a alta capacidade do vírus em provocar uma "amnésia imunológica", o qual diminui os anticorpos preexistentes que fornecem proteção a outros patógenos, tais efeitos proporcionam a vulnerabilidade à doenças secundárias e aumentam a morbimortalidade por anos após a infecção do sarampo, contudo, tais consequências não foram observadas em indivíduos vacinados.

Além do sarampo, atualmente a pandemia do Covid-19 constitui uma Emergência de Saúde pública de Importância Internacional ocasionando mais de 559.998 óbitos a nível mundial, nesse sentido, reconhecendo o impacto dos imunobiológicos, diversas instituições atuam com objetivo de desenvolver uma vacina (BRASIL, 2020).

A vista disso, pesquisadores apontam a hipótese da ação da vacina Bacille Calmette-Guérin (BCG) na atenuação dos efeitos da Covid-19, alegando que países onde a BCG é mantida de forma rotineira exibem menor incidência de casos, entretanto, embora as agências e entidades especializada em saúde relatem não haver evidências de tal relação, apontam efeitos inespecíficos da BCG sob o sistema imunológico e, dessa forma, incentivam ensaios clínicos para avaliar os efeitos da vacina (OMS; SMIm, 2020). 
Tais dados corroboram os benefícios da imunização de forma direta e indireta a determinadas patologias e, com graduandos e profissionais da saúde atuando como linha de frente aos desafios de saúde, a manutenção do cartão vacinal é fundamental.

Referente ao perfil acadêmico dos participantes, considerando a situação vacinal em função do curso, apenas Enfermagem apresentou maior percentual de indivíduos com cartão vacinal atualizado enquanto nos cursos de Nutrição e Biomedicina prevaleceu a situação de cartão desatualizado ( $p<0,0001)$. Quanto à prática de estágio extracurricular, fazê-lo esteve associado ao cartão atualizado ( $p=0,0008)$, assim como sua exigência ( $p=0,0035)$. Ademais, a declaração de conhecimento do $P N I \quad(p=0,0001)$ e a ciência das consequências trazidas ao profissional sem imunização adequada $(p=0,0141)$ também estiveram associadas a possuir cartão atualizado (Tabela 2 ).

Tabela 2 - Perfil acadêmico dos participantes do estudo de acordo com as variáveis da pesquisa, segundo a situação do cartão vacinal.

\begin{tabular}{|c|c|c|c|}
\hline \multirow[b]{2}{*}{ Variável } & \multicolumn{2}{|c|}{ Situação do cartão vacinal } & \multirow[b]{2}{*}{ p-valor* } \\
\hline & $\begin{array}{l}\text { Atualizado } \\
n ; \%\end{array}$ & $\begin{array}{l}\text { Não atualizado } \\
n ; \%\end{array}$ & \\
\hline \multicolumn{4}{|l|}{ Curso } \\
\hline Enfermagem & $96 ; 53,7^{b}$ & $41 ; 22,9^{a}$ & \multirow{4}{*}{$<0,0001^{\dagger}$} \\
\hline Farmácia & $26 ; 14,5$ & $29 ; 16,2$ & \\
\hline Nutrição & $28 ; 15,6^{a}$ & $47 ; 26,3^{b}$ & \\
\hline Biomedicina & $29 ; 16,2^{\mathrm{a}}$ & $62 ; 34,6^{b}$ & \\
\hline \multicolumn{4}{|c|}{ Faz estágio extracurricular } \\
\hline Sim & $52 ; 29,2^{b}$ & $26 ; 14,5^{a}$ & \multirow{2}{*}{$0,0008^{\dagger}$} \\
\hline Não & $126 ; 70,8^{a}$ & $153 ; 85,5^{b}$ & \\
\hline \multicolumn{4}{|c|}{ Exigência do cartão no estágio extracurricular } \\
\hline Sim & $35 ; 67,3^{b}$ & $8: 30,8^{a}$ & \multirow{2}{*}{$0,0035^{\dagger}$} \\
\hline Não & $17 ; 32,7^{a}$ & $18 ; 69,2^{b}$ & \\
\hline \multicolumn{4}{|c|}{$\begin{array}{l}\text { Ciência de que os profissionais de saúde devem } \\
\text { seguir um calendário vacinal }\end{array}$} \\
\hline Sim & $163 ; 92,6$ & $165 ; 92,7$ & \multirow{2}{*}{1,0000} \\
\hline Não & $13 ; 7,4$ & $13 ; 7,3$ & \\
\hline \multicolumn{4}{|c|}{ Orientações sobre a importância da imunização } \\
\hline Sim & $142 ; 79,8$ & $139 ; 79,4$ & \multirow{2}{*}{1,0000} \\
\hline Não & $36 ; 20,2$ & $36 ; 20,6$ & \\
\hline \multicolumn{4}{|c|}{ Conhece o Programa Nacional de Imunização } \\
\hline Sim & $98 ; 55,4^{b}$ & $59 ; 33,9^{a}$ & \multirow{2}{*}{$0,0001^{\dagger}$} \\
\hline Não & $79 ; 44,6^{\mathrm{a}}$ & $115 ; 66,1^{\mathrm{b}}$ & \\
\hline \multicolumn{4}{|c|}{$\begin{array}{l}\text { Ciência das consequências trazidas ao profissional } \\
\text { sem imunização adequada }\end{array}$} \\
\hline Sim & $167 ; 93,8^{b}$ & $152 ; 85,9^{a}$ & \multirow{2}{*}{$0,0141^{\dagger}$} \\
\hline Não & $11 ; 6,2^{\mathrm{a}}$ & $25 ; 14,1^{\mathrm{b}}$ & \\
\hline
\end{tabular}

Legenda: *Teste Exato de Fisher ou Teste G de independência/Análise de Resíduos do Qui-Quadrado. tEstatisticamente significativo. aFrequência menor que a esperada ao acaso. ${ }^{b}$ Frequência maior que a esperada ao acaso. Fonte: Chaves ECR, et al., 2020.

Estudos sobre acidentes com material biológico em profissionais de saúde demonstram maior incidência na equipe de enfermagem devido, sobretudo, sua precoce assistência direta com pacientes e à execução de procedimentos invasivos (ex. administração de medicamentos parenterais, punção venosa e soroterapia), com isso, diante da vulnerabilidade, infere-se que a percepção de risco os configura quanto a utilização dos meios de prevenção, proporcionandomaior acesso às vacinas ainda durante a formação (JUNIOR EPS, et al., 2015; SOARES WKR, et al., 2018).

Notadamente, os fatores de exposição ocupacional influenciam a profilaxia pré-exposição, todavia, Soares WKR, et al. (2018) relata também a prevalência de acidentes em profissionais atuantes em laboratório de análises clinicas, no entanto, de acordo com os dados da pesquisa, esse fator não apresentou influencia quanto a sensibilização dos discentes à imunização. 
O ambiente laboratorial de análises clínicas é caracterizado pela ampla manipulação de materiais potencialmente infecciosos, especialmente perfurocortante, o qual apresenta alta incidência em acidentes com profissionais e graduandos da saúde e, dentre esses, destacam-se biomédicos e farmacêuticoscom ampla atuação, sobretudo, na coleta e exames laboratoriais, sendo praticas recorrentes nas atividades acadêmicas (JUNIOR EPS, et al., 2015; ANAHP, 2017). A explicita exposição aos riscos adjuntos ao status vacinal inadequado, exibe o grau de negligencia dessa população, expondo o mesmo perfil aos acadêmicos de Nutrição, inferindo-se à falsa percepção de segurança.

Outro fator observado na população em estudo é a manutenção do cartão vacinal aos que praticam estágio extracurricular, pode-se corroborar essa relação ao percentual significativo de exigência por parte das empresas e instituições à comprovação do cartão vacinal atualizado para realização das atividades. Sendo práticas voluntárias e/ou remunerada, muitos estudantes iniciam precocemente sem o conhecimento prévio das normas de biosseguranças, gerando uma maior probabilidade de infecções por doenças imunopreveníves, nesse sentido, essas instituições detêm forte influência sob avaliação e a manutenção do cartão vacinal, além de auxiliar indiretamente na detecção de falhas na imunização (SORGATTO SV, et al., 2018).

Além disso, alunos que declaram conhecimento acerca do PNI e das consequências a não imunização possuem maior cobertura vacinal, sendo consistente com a dados de Araújo TM, et al. (2019). Sorgatto SV, et al. (2018), remete as falhas das coberturas à ausência de campanhas informacionais e educativas, sobretudo, nas fases iniciais da graduação.

Allcott H e Gentzkow M (2017) definem as Fake News como "artigos noticiosos que são intencionalmente falsos e aptos a serem verificados como tal, e que podem enganar os leitores". Atualmente, estudos apontam a influência dessas informações sob a recusa vacinal e à desinformação (ARROYO LH, et al., 2020; CHAVES ECR, et al., 2020). Tais dados instigaram a investigação da existência de associação desse fator com a possível desatualização do cartão vacinal, no entanto, não foi observada associação significativa entre a situação do cartão vacinal e os aspectos relacionados às fakenews (Tabela 3).

Tabela 3 - Distribuição dos participantes da pesquisa de acordo com os aspectos relacionados aos obstáculos da imunização e aveiculação de notícias falsas, segundo a situação do cartão vacinal.

\begin{tabular}{|c|c|c|c|}
\hline \multirow[b]{2}{*}{ Perguntas } & \multicolumn{2}{|c|}{ Situação do cartão vacinal } & \multirow[b]{2}{*}{ p-valor* } \\
\hline & $\begin{array}{c}\text { Atualizado } \\
n ; \%\end{array}$ & $\begin{array}{c}\text { Não atualizado } \\
n ; \%\end{array}$ & \\
\hline \multicolumn{4}{|l|}{ Obstáculos } \\
\hline Demora/filas & $86 ; 48$ & $84 ; 46,9$ & \multirow{6}{*}{0,4299} \\
\hline Traumas/Sintomas após vacinação & $18 ; 10,1$ & $21 ; 11,7$ & \\
\hline Informações vinculadas por mídias sociais & $38 ; 21,2$ & $42 ; 23,5$ & \\
\hline Mídias sociais e Demora ou Traumas & $15 ; 8,4$ & $12 ; 6,7$ & \\
\hline Demora e Traumas & $06 ; 3,4$ & $01 ; 0,6$ & \\
\hline Nenhum & $16 ; 8,9$ & $19 ; 10,6$ & \\
\hline \multicolumn{4}{|l|}{ Já viu alguma "Fake News" relacionada à vacina? } \\
\hline $\operatorname{Sim}$ & $151 ; 85,3$ & $150 ; 85,7$ & \multirow{2}{*}{1,0000} \\
\hline Não & $26 ; 14,7$ & $25 ; 14,3$ & \\
\hline \multicolumn{4}{|l|}{ Quantas frases do tipo "Fake News" já viu? } \\
\hline Ao menos uma & $65 ; 36,3$ & $80 ; 44,7$ & \multirow{5}{*}{0,4662} \\
\hline Ao menos duas & $50 ; 27,9$ & $38 ; 21,2$ & \\
\hline Ao menos três & $22 ; 12,3$ & $19 ; 10,6$ & \\
\hline Todas & $17 ; 9,5$ & $15 ; 8,4$ & \\
\hline Nenhuma & $25 ; 14$ & $27 ; 15,1$ & \\
\hline \multicolumn{4}{|c|}{$\begin{array}{c}\text { Informação do tipo "Fake News"causou impacto a } \\
\text { ponto de não procurar vacina? }\end{array}$} \\
\hline Sim & $12 ; 7,8$ & $13 ; 8,3$ & \multirow[b]{2}{*}{1,0000} \\
\hline Não & $141 ; 92,2$ & $144 ; 91,7$ & \\
\hline
\end{tabular}

Legenda: *Teste Exato de Fisher ou Teste G de independência. Fonte: Chaves ECR, et al., 2020. 
Apesar de não ter sido observada associação estatisticamente significativa nessa população, não se minimiza a repercussão dos grupos antivacinas frente a resistência em vacinar e a frequentes surtos e epidemias de doenças antes controladas, como o sarampo, além da ameaça ao retorno de patologias erradicadas, como a poliomielite (BRASIL, 2020).

Atualmente, os meios midiáticos constituem um terreno fértil para difusão de conteúdo devido à extensa utilização e a dificuldade de rastrear a fonte de origem, dessa forma, usuários tendem a dispor credibilidade diante das informações e se moldar de acordo com grupos influentes, ademais, a ampliação do acesso e o uso inconsciente desses recursos permitiu a mais notada influência sob questões de saúde (ALLCOTT H e GENTZKOW M, 2017; BRASIL, 2020; CHAVES ECR, et al., 2020).

No que diz respeito ao quantitativo de vacinas administradas por curso, foi possível observar que a menor variedade de vacinas ( 1 a 2) esteve relacionada ao curso de Biomedicina enquanto observou-se proporção maior que a esperada ao acaso de alunos do curso de Enfermagem entre os que fizeram uso de 3 a 4 vacinas diferentes $(p=0,0389)$ (Tabela 4).

Tabela 4 - Perfil dos participantes do estudo de acordo com as variáveis, segundo o número de vacinas administradas.

\begin{tabular}{|c|c|c|c|c|}
\hline \multirow[b]{2}{*}{ Variável } & \multicolumn{3}{|c|}{ Número de vacinas relatado } & \multirow[b]{2}{*}{ p-valor* } \\
\hline & $\begin{array}{l}1 \text { a } 2 \\
n ; \%\end{array}$ & $\begin{array}{l}3 \text { a } 4 \\
n ; \%\end{array}$ & $\begin{array}{l}5 \text { a } 7 \\
n ; \%\end{array}$ & \\
\hline \multicolumn{5}{|l|}{ Curso } \\
\hline Enfermagem & $31 ; 28,4^{a}$ & $56 ; 47,9^{b}$ & $34 ; 42,5$ & \multirow{4}{*}{$0,0389^{\dagger}$} \\
\hline Farmácia & $20 ; 18,3$ & $16 ; 13,7$ & $08 ; 10$ & \\
\hline Nutrição & $22 ; 20,2$ & $24 ; 20,5$ & $16 ; 20$ & \\
\hline Biomedicina & $36 ; 33,1^{b}$ & $21 ; 17,9^{a}$ & $22 ; 27,5$ & \\
\hline \multicolumn{5}{|l|}{ Sexo } \\
\hline Masculino & $22 ; 22,3$ & $23 ; 19,7$ & $18 ; 20$ & \multirow{2}{*}{0,8879} \\
\hline Feminino & $77 ; 77,7$ & $94 ; 80,3$ & $72 ; 80$ & \\
\hline \multicolumn{5}{|c|}{ Faixa etária (anos) } \\
\hline $18 H_{22}$ & $89 ; 81,6$ & $92 ; 78,6$ & $54 ; 67,5$ & \multirow{3}{*}{0,0645} \\
\hline $23 Н 27$ & $16 ; 14,7$ & $15 ; 12,8$ & $14 ; 17,5$ & \\
\hline$\geq 28$ & $04 ; 3,7$ & $10 ; 8,6$ & $12 ; 15$ & \\
\hline
\end{tabular}

Legenda: *Teste G de independência/Análise de Resíduos do Qui-Quadrado. †Estatisticamente significativo. aFrequência menor que a esperada ao acaso. bFrequência maior que a esperada ao acaso.

Fonte: Chaves ECR, et al., 2020.

Perante o exposto, pesquisas utilizando questionário autoaplicáveis possuem como limitação o viés de memória. Com isso, o status vacinal autorrelatado pode ser tendencioso quanto a real situação do entrevisto devido, sobretudo, às visões pré-estabelecidas como desejáveis. Entretanto, a frequência de respostas compatíveis com os relatos da literatura valida os resultados obtido nesse estudo (SILVA RGM e NASCIMENTO VF, 2017; ARAÚJO TM, et al., 2019; KARLSSON LC, et al.,2019).

No Brasil, distribuição das vacinas de forma rotineira possibilitou a erradicação da varíola, eliminação da poliomielite e controle diversas doenças infectocontagiosas, portanto, ratifica sua contribuição em meio a saúde públicas (ARROYO LH, et al., 2020; CHAVES ECR, et al., 2020). Os dados reforçam a preocupação dos alunos de Enfermagem frente às medidas de prevenção, devido o maior relato na administração de vacinas, todavia, expõem a negligencia dos demais cursos em presença da menor frequência registrada.

Karlsson LC, et al. (2019) enfatiza a problemática da não imunização das profissionais da saúde à recomendação da vacina, embora um elevado percentual de profissionais da saúde assegure a imunização, dentre os mesmos é frequente atitudes opostas com influência na coletividade,uma vez que estes detêm a menor disponibilidade em recomendarvacinação devido a menor confianças e/ou carência de informações baseadas em evidencias, sendo esse o indicador de conhecimento. 
Sorgatto SV, et al. (2018) que o maior percentual de estudantes com todas as vacinas do calendário para adultos é justificado pela solicitação do cartão de vacinação forma rotineira pela universidade expondo a real contribuição das instituições de ensino na exigência da comprovação vacinal no ato da matricula, nas avaliações e manutenção constantes do cartão de vacinação dos discentes. Nesse contexto, além de campanhas de nível educacional aos discentes, é essencial estabelecer o comprometimento das instituições superiores nas avaliações do status vacinal ainda na graduação (MPH SBD, et al., 2018; KARLSSON LC, et al., 2019).

Considerando o curso de graduação a declaração relacionada ao ano em que o aluno recebeu orientações sobre a importância da imunização, notou-se maior frequência de alunos de Farmácia e Nutrição que declararam tê-las recebido no $1^{\circ}$ ano do curso, enquanto os alunos de Enfermagem declararam, em sua maioria, que esses fatos ocorreram no $2^{\circ}$ ano $(p<0,0001)$.

Quanto ao conhecimento do PNI, observou-se associação entre a declaração de conhece-lo e o curso de Enfermagem e entre os cursos de Nutrição e Biomedicina e o autorrelato de desconhecimento desse Programa $(p<0,0001)$ (Tabela 5).

Tabela 5 - Perfil dos participantes do estudo de acordo com as variáveis, segundo o curso de graduação.

\begin{tabular}{|c|c|c|c|c|c|}
\hline \multirow[b]{2}{*}{ Variável } & \multicolumn{4}{|c|}{ Curso } & \multirow[b]{2}{*}{ p-valor } \\
\hline & $\begin{array}{c}\text { Enfermagem } \\
n ; \%\end{array}$ & $\begin{array}{c}\text { Farmácia } \\
\quad n ; \%\end{array}$ & $\begin{array}{c}\text { Nutrição } \\
n ; \%\end{array}$ & $\begin{array}{c}\text { Biomedicina } \\
n ; \%\end{array}$ & \\
\hline \multicolumn{6}{|c|}{$\begin{array}{l}\text { Orientações sobre a } \\
\text { importância da imunização }\end{array}$} \\
\hline $\operatorname{Sim}$ & $115 ; 82,1$ & $40 ; 74,1$ & $55 ; 73,3$ & $75 ; 84,3$ & \multirow{2}{*}{0,2177} \\
\hline Não & $25 ; 17,9$ & $14 ; 25,9$ & $20 ; 26,7$ & $14 ; 15,7$ & \\
\hline \multicolumn{6}{|c|}{ Orientações recebidas } \\
\hline $1^{\circ}$ ano & $39 ; 32,5^{a}$ & $27 ; 71^{b}$ & $47 ; 79,7^{b}$ & $39 ; 41,9$ & \multirow{4}{*}{$<0,0001^{\dagger}$} \\
\hline $2^{\circ}$ ano & $75 ; 62,5^{\mathrm{b}}$ & $07 ; 18,4^{a}$ & $5 ; 8,5^{a}$ & $43 ; 46,3$ & \\
\hline 3 ano & $6 ; 5$ & $02 ; 5,3$ & $7 ; 11,8$ & $11 ; 11,8$ & \\
\hline $4^{\circ}$ ano & 0 & $02 ; 5,3^{b}$ & 0 & 0 & \\
\hline \multicolumn{6}{|c|}{ Conhece o PNI } \\
\hline Sim & $79 ; 57,2^{b}$ & $28 ; 51,9$ & $20 ; 26,3^{a}$ & $30 ; 34,1^{a}$ & \multirow{2}{*}{$<0,0001^{\dagger}$} \\
\hline Não & $59 ; 42,8^{a}$ & $26 ; 48,1$ & $56 ; 73,7^{b}$ & $58 ; 65,9^{b}$ & \\
\hline
\end{tabular}

Legenda: Teste G de independência/Análise de Resíduos do Qui-Quadrado. †Estatisticamente significativo. aFrequência menor que a esperada ao acaso. bFrequência maior que a esperada ao acaso.

Fonte: Chaves ECR, et al., 2020.

Ao analisar a Matriz Curricular dos cursos, foi observado a inserção do assunto relacionado a imunização a partir do $1^{\circ}$ ano da graduação através da disciplina Biossegurança, inferindo a maior frequência de orientações relatadas pelos graduandos de Farmácia e Nutrição, todavia, a menor adesão vacinal por eles, assim como menor relato de orientações dos demais cursos podem ter origem da imaturidade educacional nos primeiros semestres e, portanto, o descaso às disciplinas.

Oliveira VA, et al. (2011) expõe que $60,4 \%$ dos servidores da saúde não participaram das disciplinas de Biossegurança e, contrapondo-o, Nunes AO, et al. (2015) relata $60,2 \%$ de participação, contudo, menor frequência de vacinação entre os que não participaram. Tal realidade aponta a biossegurança como norteador às práticas de autoproteção no contexto da graduação e ocupação profissional.

Quanto ao curso de Enfermagem, compreende-se os maiores relatos no $2^{\circ}$ ano devido a disponibilidade de três disciplinas contribuintes: Epidemiologia, Semiotécnica em enfermagem e Saúde da Criança e do Adolescente, temas que trazem a inserção dos conceitos de imunização, prevenção de agravos e indicadores de saúde (BRASIL, 2018). 
Referente ao conhecimento do $\mathrm{PNI}$, o menor relato de conhecimentos adjunto a baixa vacinação presente no curso de Nutrição e Biomedicina, ressalta a necessidade da adequação das matrizes curriculares aos padrões exigidos à prática, com vista na atualização contínua de informações que fortaleçam questões preventivas, principalmente vacinação, devido aos riscos constantes com material biológico, além de adaptálas ao contexto atual das necessidades sociais e às alterações no cenário de saúde (BRASIL, 2018; FERREIRA MJM, et al., 2019).

Considerando o curso de graduação, observou-se que o curso de Enfermagem esteve associado à exigência do cartão de vacinação no Estágio extracurricular enquanto os demais cursos estiveram associados à sua não exigência $(<0,0001)$. Além disso, observou-se associação entre a declaração de ciência de que os profissionais de saúde devem seguir um calendário vacinal e o curso de Enfermagem e o curso de Nutrição e o autorrelato de desconhecimento desse aspecto $(p=0,0381)$ (Tabela 6$)$.

Tabela 6 - Perfil dos participantes do estudo de acordo com as variáveis, segundo o curso de graduação.

\begin{tabular}{|c|c|c|c|c|c|}
\hline \multirow[b]{2}{*}{ Variável } & \multicolumn{4}{|c|}{ Curso } & \multirow[b]{2}{*}{ p-valor* } \\
\hline & $\begin{array}{c}\text { Enfermagem } \\
\boldsymbol{n} ; \%\end{array}$ & $\begin{array}{c}\text { Farmácia } \\
n ; \%\end{array}$ & $\begin{array}{c}\text { Nutrição } \\
n ; \%\end{array}$ & $\begin{array}{c}\text { Biomedicina } \\
n ; \%\end{array}$ & \\
\hline \multicolumn{6}{|c|}{$\begin{array}{l}\text { Exigência do cartão de } \\
\text { vacinação no ato da matrícula }\end{array}$} \\
\hline $\begin{array}{l}\text { Sim } \\
\text { Não }\end{array}$ & $\begin{array}{c}0 ; 0 \\
140 ; 100\end{array}$ & $\begin{array}{c}0 ; 0 \\
55 ; 100\end{array}$ & $\begin{array}{c}0 ; 0 \\
77 ; 100\end{array}$ & $\begin{array}{c}0 ; 0 \\
91 ; 100\end{array}$ & 1,0000 \\
\hline \multicolumn{6}{|c|}{$\begin{array}{l}\text { Exigência do cartão de } \\
\text { vacinação no Estágio } \\
\text { extracurricular }\end{array}$} \\
\hline $\begin{array}{l}\text { Sim } \\
\text { Não }\end{array}$ & $\begin{array}{c}32 ; 22,9^{\mathrm{b}} \\
108 ; 77,1^{\mathrm{a}}\end{array}$ & $\begin{array}{c}2 ; 3,7^{\mathrm{a}} \\
52 ; 96,3^{\mathrm{b}}\end{array}$ & $\begin{array}{c}4 ; 5,2^{\mathrm{a}} \\
73 ; 94,8^{\mathrm{b}}\end{array}$ & $\begin{array}{c}5 ; 5,5^{\mathrm{a}} \\
86 ; 94,5^{\mathrm{b}}\end{array}$ & $<0,0001^{\dagger}$ \\
\hline \multicolumn{6}{|c|}{$\begin{array}{l}\text { Ciência de que os } \\
\text { profissionais de saúde devem } \\
\text { seguir um calendário vacinal }\end{array}$} \\
\hline $\begin{array}{l}\text { Sim } \\
\text { Não }\end{array}$ & $\begin{array}{c}134 ; 96,4^{b} \\
05 ; 3,6^{a}\end{array}$ & $\begin{array}{c}49 ; 90,7 \\
05 ; 9,3\end{array}$ & $\begin{array}{l}65 ; 85,5^{\mathrm{a}} \\
11 ; 14,5^{\mathrm{b}}\end{array}$ & $\begin{array}{c}85 ; 94,4 \\
05 ; 5,6\end{array}$ & $0,0381^{\dagger}$ \\
\hline
\end{tabular}

Legenda: *Teste G de independência/Análise de Resíduos do Qui-Quadrado. †Estatisticamente significativo. aFrequência menor que a esperada ao acaso. ${ }^{b}$ Frequência maior que a esperada ao acaso.

Fonte: Chaves ECR, et al., 2020.

Os dados reforçam a necessidade da exigência por parte dos estágios do cartão de vacinação, haja vista sua influência na manutenção do mesmo, dessa forma, ressalta a importância das instituições de ensino ajustar a documentação às práticas de estágio com vista na observação do status vacinal dos discentes, servindo como uma forma de alertá-los as irregularidades.Ademais, o perfil do aluno de Nutrição ratifica questões de compromisso responsável das instituições em fornecer uma educação permanente sobre imunização e expor os reais riscos presentes aos alunos não imunizados (FERREIRA MJM, et al., 2019; KARLSSON LC, et al., 2019).

\section{CONCLUSÃO}

Observa-se negligencias quanto ao perfil vacinal acadêmico a partir do cenário da baixa frequência de vacinação, o elevado grau de risco, a baixa percepção acerca das consequências a não imunização e dos programas de prevenção disposto aos graduandos da área da saúde, é fundamental à instituição de ensino pautar a necessidade de medidas preventivas, a partir da intensificação de cuidados em nível da biossegurança, verificação precoce e constante do cartão de vacinação, com início no ato da matrícula. Ademais, visto que se observou relação entre o cartão atualizado e declaração de conhecimento do PNI, é válida a ampliação de forma contínua as abordagens que orientem a cerca dessa temática durante as disciplinas, para assim melhor fornecer a educação, orientação e supervisão dos estudantes no processo de formação acadêmica. 


\section{REFERÊNCIAS}

1. ALLCOTT H e GENTZKOW M. Social media and fake news in the 2016 election. Journal of Economic Perspectives, 2017;31(2):211-236.

2. APS LRMM, et al. Eventos adversos de vacinas e as consequências da não vacinação: uma análise crítica. Rev Saúde Pública, São Paulo, 2018; 52(40).

3. ARAÚJO TM, et al. Vacinação e fatores associados entre trabalhadores da saúde. Cad. Saúde Pública 2019; 35(4).

4. ARROYO LH, et al. Áreas com queda da cobertura vacinal para BCG, poliomielite e tríplice viral no Brasil (20062016): mapas da heterogeneidade regional. Cad. Saúde Pública 2020; 36(4).

5. ASSOCIAÇÃO NACIONAL DE HOSPITAIS PRIVADOS (ANAHP). Acidentes com perfurocortantes têm alta incidência no setor. São Paulo, 2017.

6. BRASIL. Ministério da Saúde. Portaria n597, de 8 de abril de 2004. Institui, em todo território nacional, os calendários de vacinação, 2004.

7. BRASIL. Lei № 11.788, de 25 de setembro de 2008. Dispõe sobre o estágio de estudantes; altera a redação do art. 428 da Consolidação das Leis do Trabalho - CLT, aprovada pelo Decreto-Lei no 5.452, de 10 de maio de 1943, e a Lei no 9.394, de 20 de dezembro de 1996, 2008.

8. BRASIL. Plenário do Conselho Nacional de Saúde (CNS). Resolução no 573, de 31 de janeiro de 2018. Recomendações do Conselho Nacional de Saúde à proposta de Diretrizes Curriculares Nacionais (DCN) do curso de graduação Bacharelado em Enfermagem, 2018.

9. BRASIL. Câmara dos Deputados. Projeto de Lei n`3530 de 2019 Dispõe sobre a obrigatoriedade da apresentação da caderneta de vacinação ou equivalente nos casos em que especifica, 2019.

10. BRASIL. Câmara dos Deputados. Projeto de Lei $n^{\circ} 1.429$ de 2019. Estabelece a obrigatoriedade de apresentação da Caderneta de Saúde da Criança quando da matrícula de aluno nas redes públicas e privadas de educação; tendo parecer da Comissão de Educação, 2019.

11. BRASIL. Conselho Regional de Farmácia do Estado de São Paulo. Análises Clínicas e Toxicológica. São Paulo, 2020; 5:58.

12. BRASIL. Ministério da Saúde. Vigilância Epidemiológica do sarampo no Brasil. Boletim Epidemiológico Semanas Epidemiológicas 1 A 23, 2020.

13. BRASIL. Ministério da Saúde. Secretaria de Vigilância em Saúde. Departamento de Imunização e Doenças Transmissíveis. Manual dos Centros de Referência para Imunobiológicos Especiais. Brasília, 2019; 5.

14. BRASIL. Ministério da Saúde. Boletim Epidemiológico Especial. Doença pelo Coronavírus COVID-19, $2020 ; 1$.

15. BRAZ RM, et al. Classificação de risco de transmissão de doenças imuno preveníveis a partir de indicadores de coberturas vacinais nos municípios brasileiros. Epidemiol. Serv. Saúde, 2016; 25(4).

16. CARDIN VSG e NERY LMG. Vaccination hesitation: constitutional right to individual autonomy or an attack on collective protection? Prisma Jur., São Paulo, 2019;18(2);224-240.

17. CHEHUEN N, et al. Situação Vacinal Dos Discentes Da Faculdade De Medicina Da UFJF-Mg. Rev. Bras. Educ. Med, 2010;34(2): 270-277.

18. CHAVES ECR, et al. Avaliação da cobertura vacinal do sarampo no período de 2013-2019 e sua relação com a reemergência no Brasil. Revista Eletrônica Acervo Saúde, 2020;(38):1982.

19. DURÃES FAA, et al. Edward Jenner e a Primeira Vacina: estudo do discurso expositivo adotado em um Museu de Ciência Khronos, Revista de História da Ciência, São Paulo, 2019;7: 1-15.

20. FERREIRA MJM, et al. Novas Diretrizes Curriculares Nacionais para os cursos de Medicina: oportunidades para ressignificar a formação. Interface (Botucatu), 2019;23(1).

21. GOMES SCR e CALDAS AJM. Incidência de acidentes de trabalho com exposição a material biológico em profissionais de saúde no Brasil, 2010-2016. Rev Bras Med Trab. 2019;17(2):188-200.

22. JUNIOR EPS, et al. Acidente de trabalho com material perfurocortante envolvendo profissionais e estudantes da área da saúde em hospital de referência. Rev Bras Med Trab., 2015;13(2):69-75.

23. KARLSSON LC, et al. A associação entre confiança, comportamento e vontade de recomendar vacinas entre profissionais de saúde finlandeses. PLoS ONE, 2019;14(10).

24. MINA MJ, et al. A infecção pelo vírus do sarampo diminui os anticorpos preexistentes que oferecem proteção contra outros patógenos. Ciência, 2019;366(6465):599-606.

25. MORAIS RLGL, et al. Conhecimentos e condutas de biossegurança entre docentes de enfermagem. Rev Fund Care Online, Bahia, 2017; 9(1):137-143.

26. MPH SBD, et al. Políticas de vacinação entre escolas profissionais de saúde: evidências de imunidade e tolerância a isenções de vacinação. Controle de Infecção Hosp Epidemiol. 2015;36 (2):186-191

27. NEGRINHO NBS, et al. Fatores associados à exposição ocupacional com material biológico entre profissionais de enfermagem. Rev Bras Enferm São Paulo, 2017;70(1):133-8.

28. NUNES AO, et al. Vacinação contra hepatite b em trabalhadores da saúde de um município da Bahia. Rev. Saúde Col. UEFS, Feira de Santana, 2015;5(1): 9-16.

29. OLIVEIRA VA, et al. Situação vacinal e sorológica para a hepatite B em profissionais da estratégia saúde da família. Revista Rene, 2011; 12(1): 960.

30. ORGANIZAČÃO PANAMERICANA DE SAÚDE (OPS). Saúde do Trabalhador. Washington, 2012.

31. ORGANIZAÇÃO MUNDIAL DA SAÚDE. Vacinação Bacille Calmette-Guérin (BCG) e COVID-19, 2020.

32. SANTOS JR. Elaboração do mapa de risco do laboratório de mecânica dos solos e topografia na construtora Milão LTDA. UNI - anhanguera - Centro Universitário De Goiás Curso De Engenharia Civil. Goiânia, 2018.

33. SOCIEDADE BRASILEIRA DE IMUNOLOGIA. Bacille Calmette-Guérin (BCG) vaccination and COVID-19, 2020.

34. SORGATTO SV, et al. Situação vacinal de acadêmicos da área da saúde de uma universidade. J. nurs. health. 2018;8(2).

35. SILVA RGM e NASCIMENTO VF. Cobertura Vacinal entre Acadêmicos de Enfermagem. J Health Sci 2017;19(4):26873.

36. SOARES WKR, et al. Incidência de acidentes com perfurocortantes em profissionais de saúde em um hospital de grande porte na Amazônia Legal. Braz. J. Hea. Rev., Curitiba, 2018;1(1):51-69.

37. SOCIEDADE BRASILEIRA DE IMUNIZAÇÕES (SBIm). Calendário de vacinação ocupacional, 2019/2020. 